\title{
SPORT-RELATED TRAUMATIC INJURIES AMONG SCHOOLCHLDREN (A QUESTIONNAIRE STUDY)
}

\author{
Vlasta Merglova \\ Dentistry Department, Faculty of Medicine in Pilsen, Charles University in Prague, Czech Republic \\ Address for coprespondence: \\ Vlasta Merglova \\ Dentistry Department, Faculty Hospital \\ Alej Svobody 80, 30480 Pilsen, Czech Republic \\ E-mail: merglovav@fnplzen.cz
}

\begin{abstract}
Ahstract Background: Childhood represents a risk period of susceptibility to sport-related injuries.
Objectives: The aim of the study was to investigate the prevalence of sports-related injuries including orofacial traumas in children attending primary schools and participating in competitive sports, then to compare their situation with that of children engaging in sporting activities only at school and in their leisure time. The second aim of the study was concentrated on the use of sports mouthguards.

Methods: Data was obtained by means of a questionnaire and statistically analysed by the basic statistic methods in Microsoft Office Excel and Pearson's chi-square test, and a statistical significance level $p<0.05$ was established.

Results: 341 children (175 girls and 166 boys) completed the questionnaires and $204(59.8 \%)$ of them were competitive athletes. $146(42.8 \%)$ children reported sports-related injuries and $47(13.8 \%)$ children registered trauma of the orofacial region. Only 10 $(2.9 \%)$ children regularly use sports mouthguards. No statistically significant differences were detected in the occurrence of sport-related injuries including orofacial traumas between the competitive athletes and non-competitive children.

Conclusion: Sport-related trauma represents a risk not only for children engaging in competitive sport activities but also for children doing sports at school and occasionally in their free time.
\end{abstract}

Key WOrdls dental trauma, dentoalveolar trauma, sport mouthguard

\section{Introduction}

Childhood represents a high risk period in terms of susceptibility to injury. Children may cause themselves not only serious injuries which result in hospitalisation, in some cases invalidity or even death, but also non-lifethreatening injuries in the orofacial area. Injury or invalidity, especially if it involves movement, the human senses or physical appearance, often leads to intense anxiety and stress, which threatens the healthy creation of a personal identity. Injuries to the face, jaw, oral cavity and teeth are problems which in the long term worsen the quality of life of the child and burden the family financially (Poritt, Dawn Rodd, Baker, 2011). Traumatic dental injuries (TDI) account for $5 \%$ of all injuries for which medical advice is sought; in the case of pre-school children the figure is as 
high as $17 \%$ (Andersson, 2013). Dental trauma in children most occurs in the period of growth and development of the orofacial area; treatment is often complicated, long-term and requires special care.

The literature provides various data concerning dental injuries in children. It is stated that $50 \%$ of adolescents have experienced dental injuries (Andreasen, Ravn, 1972). Authors from northern countries describe how $35 \%$ of minors aged 16 have had one or more dental injuries during their school attendance (Borsen, Holm, 1997).

Recent years have seen an increase in the number of injuries involving teeth and jaw in children. The causes of dental injuries may be divided into the unpredictable (falls, collisions, blows to the orofacial region) and the predictable, which include injuries sustained during sports activities. The most common causes of dental injuries include falling whilst running, tripping up or slipping, as well as being struck in the mouth by objects, various sports activities, traffic accidents and, in rare cases, the result of violence (Atabek, Alaçam, Aydintuğ, Konakoğlu, 2013; Glendor, 2008; Hecova, Tzigkounakis, Merglova, Netolicky, 2010; Lexomboon, Carlson, Andresson, von Bultzingslowen, Mensah, 2016). The situations described above account for $61 \%$ of dental injuries in children (Glendor, 2008). Damé-Teixeire (Damé-Teixeire, Severo Alves, Susin, Maltz, 2013) ascertained that from a group of 1528 12-year-old children, the most common cause of injury was a fall $(15.46 \%)$, followed by sport $(11.08 \%)$ and various collisions (10.6\%). A further frequent cause of dental injuries in children are various games (16.2\%) and sports activities (between 11.1\% and 39\%) (Glendor, 2008; Hecova et al., 2010; Lexomboon et al., 2016; DaméTeixeire et al., 2013). Other, less frequent causes of dental injuries in children are traffic accidents, fights and acts of violence (Damé-Teixeire et al., 2013). Children may cause self-inflicted dental injuries through various bad habits such as chewing on pencils or using their teeth to open hair-clips or remove bottle tops. Such behaviour accounts for between 3.3\% and $8.5 \%$ of dental injuries (Traebert, Peres, Blank, Boell, Pietruza, 2003; Taiwo, Jalo, 2011). Dental injury may also be due to iatrogenic causes, which include laryngoscopy and intubation (Glendor, 2008).

The most frequent location where children sustain dental injuries is the home $(22.3-63.2 \%)$, followed by school (8.5-36.0\%), children's playgrounds, including sports grounds (20\%), and the street (11.2-12.0\%) (DaméTeixeire et al., 2013; Bücher, Neumann, Hickel, Künish, 2013; Andreasen, Andreasen, Andersson, 2007).

There are a number of factors involved in the origin of dental injuries. These include oral factors of the child, environmental factors and the child's mode of behaviour. Dental injuries occur most frequently in children with malocclusion, protrusion of the upper incisors and poor lip closure. Other predispositional oral factors include carious and hypoplastic changes of hard dental tissues, as well as oral piercing and various bad habits associated with abnormal use of the teeth (Glendor, 2008; Hecova et al., 2010). Significant predispositional factors in dental injuries are hyperactive children, behavioural problems and child obesity (Damé-Teixeire et al., 2013). Children from divorced, incomplete or foster families also suffer more from dental injuries (Damé-Teixeire et al., 2013).

Marcenes et al. (Marcenes, Zabot, Traebert, 2001) examined the influence of socio-economic factors on the occurrence of TDI and came to the surprising conclusion that there was a higher occurrence of trauma in children from higher socio-economic groups. They account for this difference by the fact that these children have easier access to various high-risk sports.

The aim of current questionnaire survey was to ascertain the occurrence of traumatic injuries, including injuries to teeth and jaw in children participating in sports at school and also competitively, and children participating in sports at school and in their free time only recreationally. A higher prevalence of traumatic injuries, including injuries to orofacial region was anticipated in children engaged in competitive sport. The second aim of the study was concentrated on use of sports mouthguards in children. 


\section{Material and methods}

\section{Ethical considerations}

Ethical approval for the investigation was obtained from the Research Ethics Committee Faculty of Medicine in Pilsen, Charles University in Prague, Czech Republic.

\section{Data collection method}

In order to obtain data concerning the occurrence of injuries and the causes thereof, a questionnaire was designed, consisting of two parts. The first basic section of the questionnaire contained six questions for ascertaining the gender and age of the child, sports activities, means of protection used when doing sport and whether the child had suffered any injury, including an injury to the face, oral cavity and teeth. The second section contained five questions and concerned only those children who, in response to the question as to whether they had ever suffered an injury to their teeth or jaw, answered in the affirmative. The validity of the questionnaire for the purposes of current study was tested in 2011 on a group of 130 children whose average age was 14, within a project entitled "A safe environment for children without injuries from sport and other activities - with a focus on dental injuries" (Programme for the care of children and teenagers of the Ministry of Education of the Czech Republic).

As the target group for the questionnaire, children were chosen from the upper level of three primary schools with extended tuition in sport (Pilsen, Czech Republic). 400 questionnaires were delivered to 16 classes with an average of 25 pupils each. The questionnaires were sent to the parents of children via their teachers. The parents and their children completed the questionnaires together. The response rate was $80.3 \%$. Thus 341 children from the upper level of two primary schools in Pilsen participated in the questionnaire survey. These children came from both similar socio-economic and cultural backgrounds, as well as from the same district of the city.

\section{Data analysis}

For evaluating most of the questions, basic descriptive statistics were used in Microsoft Office Excel. A comparison of the number of injuries in children involved in competitive sports and children not involved in competitive sports was conducted on the basis of the Pearson chi-square test for contingency tables. A statistical significance level of $p<0.05$ was established. To this end the STATISTICA program from the StatSoft ČR firm was used.

\section{Resulls}

The questionnaire was completed by 341 pupils (175 girls and 166 boys) attending a primary school. The characteristics of respondents is mentioned in Table 1.

Tahle 1. Characteristics of respondents

\begin{tabular}{ccccccc}
\hline \multirow{2}{*}{ Number of children } & \multicolumn{2}{c}{ Gender } & Average age & & Number of competitive & \multicolumn{2}{c}{$\begin{array}{c}\text { Number of non-competitive } \\
\text { athletes }\end{array}$} & athletes \\
\cline { 2 - 4 } & girls & boys & 13 & & ates & $137(40.2 \%)$ \\
\hline 341 & $175(51.3 \%)$ & $166(48.7 \%)$ & SD $=1.25$ & & $204(59.8 \%)$ & $137(25)$ \\
\hline
\end{tabular}

SD - standard deviation.

Source: qestionnaire survey. 
The most common competitive sports amongst survey participants were soccer (58 pupils, or $28.4 \%$ ), aerobics (27 pupils, or $13.2 \%$ ), floorball (21 pupils, or 10.3\%) and ice hockey (21 pupils, or $10.3 \%$ ). 40 pupils (19.6\%) practised two sports competitively.

An injury sustained during sport was mentioned by 193 pupils (56.6\%); 144 pupils (42.8\%) stated they had suffered no sporting injuries in the past; four pupils (1.2\%) offered no response to this question.

232 children (68.0\%) use some form of protection during sport. Approximately half this number practises sport competitively. The most common used means of protection are an ice - hockey helmet and a cyclist's helmet (174 pupils, or $51.0 \%$ ). A sport-mouthguard is used only by ten pupils (eight boys and two girls), which is $2.9 \%$.

Most often children injured themselves between the ages of six and 10 years: this age category accounted for 20 pupils (42.4\%). 21 children (45.4\%) did not respond to this question.

Out of the 341 respondents, 47 had suffered injuries to teeth or the jaw. An injury to a tooth or teeth was mentioned by 38 pupils of whom 21 were boys and 17 girls. Six pupils had had jaw injuries and three pupils $(0.9 \%)$ injuries to the teeth and jaw (Table 2).

Table 2. Orofacial traumatic injuries in 341 respondents

\begin{tabular}{lc}
\hline \multicolumn{1}{c}{ Injury } & Number of children \\
\hline Dental injury & $38(11.1 \%)$ \\
Jaw injury & $6(1.8 \%)$ \\
Dental and jaw injury & $3(0.9 \%)$ \\
\hline Total & $47(13.8 \%)$ \\
\hline
\end{tabular}

Source: qestionnaire survey.

The most common type of injury in 47 respondents was a clinical crown fracture (22 children, or $46.8 \%$ ). An injury to the periodontal tissues was mentioned by 13 children $(27.7 \%)$ and a combined injury to the periodontal tissues and hard dental tissue had been suffered by three pupils (6.4\%).

Out of $47(13.8 \%)$ pupils who answered they had suffered an injury to teeth or the jaw, $33(70.2 \%)$ had sustained this injury while doing sport, most commonly soccer. The remaining 14 pupils (29.8\%) stated they had sustained their injury at school, at home or at a children's playground.

Table 3. Injuries in 341 respondents

\begin{tabular}{|c|c|c|c|c|}
\hline & \multicolumn{2}{|c|}{ Non-orofacial injuries } & \multicolumn{2}{|c|}{ Orofacial injuries } \\
\hline & competitive sport & non competitive sport & competitive sport & non competitive sport \\
\hline Number of children & $97(66.4 \%)$ & $49(33.6 \%)$ & $33(70.2 \%)$ & $14(29.8 \%)$ \\
\hline Total & \multicolumn{2}{|c|}{146} & \multicolumn{2}{|c|}{47} \\
\hline Chi square test & \multicolumn{2}{|c|}{$p=0.07$} & \multicolumn{2}{|c|}{$p=0.22$} \\
\hline
\end{tabular}

Source: questionnaire survey.

97 of those doing competitive sport from an overall total of 146 had sustained various types of injuries except orofacial traumas. In the group of children not engaged in competitive sport, the number was 49 . Using the chisquare test for contingency tables, the difference between the two groups of pupils was statistically non-significant 
$(p=0.07)$. It can therefore be stated that there was no significant difference in the number of injured children between the two groups of pupils. It is, however, clear from the data that there is a slightly higher occurrence of injury among pupils who are involved in competitive sport than among those who are not (Table 3).

33 of those doing competitive sport had suffered orofacial injuries, compared to 14 pupils not engaged in competitive sport. A comparison of the two groups was similarly conducted using the chi-square test. Again injuries to teeth and jaw were slightly more common in pupils doing competitive sport. However, using a $5 \%$ significance level, there was no statistical difference between injuries to the teeth and jaw in both groups $(p=0.22)$ (Table 3 ).

\section{Discussion}

Injuries to the teeth occur in boys and girls in primary, mixed and permanent dentition. It has been established that $71-92 \%$ of dental injuries occur before the age of 19 (Davis, Scott, 1984). Gassner et al. (Gassner, Bosch, Tuli, Emshoff, 1999) reached the conclusion that almost $50 \%$ of dental injuries occur before the age of 10 , at a time when neither teeth nor jaw are fully developed. The period of highest risk in terms of injury to teeth and jaw is at the age of 9-10 years (Andreasen, Ravn, 1972). In present sample the injuries occurred most commonly during this high risk period. The same conclusion was reached by Atabek et al. (2013). The prevalence of injuries to permanent teeth in 12 -year-old boys is given as $12-33 \%$ and in girls $4-19 \%$ (Andreasen, Ravn, 1972). Considerable differences in the occurrence of dental injuries in various epidemiological studies are probably caused by the various methods of raising children, cultural and social norms and ways of spending free time, as well as socio-economic factors, nonuniform methodology and differing diagnostic criteria. In current sample of schoolchildren, whose average age was 13 , injuries to the jaw and teeth occurred in $13.8 \%$ of those surveyed. $11.1 \%$ of children had injured only their teeth. The majority of authors (Glendor, 2008; Andreasen et al., 2007) record a significantly higher occurrence of injury in boys than in girls. In boys the prevalence of injury to permanent teeth is even twice as frequent as in girls. This difference is explained by the more risky behaviour of boys by engaging in contact sports and sports with a greater risk of teeth injuries. A difference between males and females in the occurrence of teeth injuries is also evident in university students. Biazevic et al. (2010) ascertained that the risk of dental injury is 2.78 greater for male students than females. Some studies (Skaare, Jacobsen, 2003; Rocha, Cardoso, 2001), however, indicate a reduction in the difference between boys and girls in injuries to permanent teeth: this is due to a change in the behaviour of girls, who are now beginning to engage in contact sports or high-risk sports which were previously the sole prerogative of boys and which carry a high risk of dental injury. Likewise in current study there was no pronounced difference between boys and girls in the occurrence of dental injuries. The ratio of boys to girls was $1.25: 1$. As in a series of other studies (Andersson, 2013; Hecova, 2010; Taiwo, Jalo, 2011) current questionnaire also showed the most frequent type of injury was the fracture of a clinical crown, which occurred in $46.8 \%$ cases of children with injuries to permanent teeth.

The Fédération dentaire international (FDI) divides sports according to the risk of dental injuries into high-risk and medium-risk (Federation Dentaire International, 1990). High-risk sports include American football, ice hockey, field hockey, lacrosse, martial arts, rugby, inline skating, skateboarding and mountain bike riding. Medium-risk sports include basketball, soccer, handball, diving, squash, gymnastics, parachuting and water polo. The majority of risky sports consists of so-called contact sports, in which participants come into either direct contact (boxing, martial arts, judo) or indirect contact (handball, basketball, soccer, ice hockey). The school pupils in current sample who participated in medium-risk competitive sports were most often involved in soccer and floorball, and of the 
high-risk sports ice hockey. The risk of dental injuries during sporting activities should not be underestimated. It is stated that during their sporting careers $50 \%$ of sportsmen and -women will suffer a TDI (Heintz, 1968). In every season, every participant in a contact sport has a $10 \%$ risk of a TDI (Schulze, 2008). Dental injuries occur most often during sporting encounters (69\%), while the remaining $31 \%$ are incurred during training: this is probably due to the fact that participants risk more in a proper competitive encounter (Sane, Ylipaavalniemi, 1988). Some authors (Lang et al., 2002; Ozbay et al., 2013) have studied the occurrence of dental injuries in participants of indirect contact sports such as handball and basketball. Ozbay et al. (2013) have found a $19.34 \%$ dental injury rate in handball players. The medical records of $16.6 \%$ of basketball players whose average age was 22.28 years mention dental injuries sustained during a game (Perunski et al., 2005). In present data $13.8 \%$ of pupils had sustained an injury to teeth or jaw during sport. The highest risk sport in the current sample was soccer.

The best prevention of all injuries is better information on dental injuries, the avoidance of such injuries, provision of first aid on the spot and the necessity of timely treatment. Education should be aimed not only at children and their parents but also at teachers, tutors and trainers. Dental injuries sustained during sport are foreseeable and can thus be avoided by means of a mouthguard. A significant reduction in the risk of dental injuries during sport by using a mouthguard has been demonstrated through research (Lang, Pohl, Filippi, 2002; Perunski, Lang, Pohl, Filippi, 2005). Sports mouthguards can either completely prevent or significantly reduce injuries to lips and teeth (Davis, Scott, 1984). The use of mouthguards by children and young people varies in different sports: in some sports, along with other protective elements, they form part of the participant's basic equipment. If a mouthguard is not compulsory according to the rules of the given sport, its voluntary use amongst children and young people is not especially common. Research by Rodd and Chesham (Rodd, Chesham, 1997) showed that in the 14-15 age group only $6 \%$ of youngsters use a mouthguard during sport; that number was significantly lower amongst girls and children from lower socio-economic groups. Present research came to the same conclusion with regard to the use of mouthguards amongst girls and boys. One interesting fact concerning children and mouthguards was ascertained by Fakhruddin et al. (Fakhruddin, Lawrence, Kenny, Locker, 2007), who state that only $5.5 \%$ of children use a mouthguard during sporting activities at school. A significantly higher number $(20.2 \%)$ use a mouthguard when practising competitive sport. Similarly mouthguards are used more often by participants in sport at university (19.24\%) (Skaare, Jacobsen, 2003). Only 2.9\% of children in current survey stated they use sports mouthguards. Basketball players with an average age of 22.28 years use mouthguards even less: in a questionnaire survey only $1.4 \%$ stated they use a mouthguard regularly during play (Perunski et al., 2005). The reasons for not wearing a mouthguard vary: a number of youngsters do not believe in the effectiveness of mouthguards or consider them too expensive, unaesthetic and likely to cause problems with breathing and speech. Many adolescents do not use a mouthguard because they were not advised to do so, by neither parents nor trainers. Custom-made mouthguards, professionally prepared on the basis of a dental impression, were possessed mostly by children who regularly visited the family dentist (Fakhruddin et al., 2007).

In addition, youngsters engaging in sport often sustained injuries to the soft tissue of the oral cavity and jaw, the most common being bruising and lacerations to the lips and oral mucosa. Injuries to the jaw are less frequent. Only $1.8 \%$ of the children in present survey mentioned separate jaw injuries, and $0.8 \%$ combined injuries to teeth and jaw. Likewise Gassner et al. (Gassner, Tuli, Hächl, Moreika, Ulmer, 2004) mention a greater risk of dental injury while doing sports than maxillofacial injuries. 
Current study compared the prevalence of injuries in the orofacial area in children involved in competitive sports and children doing sport only at school or recreationally. It was supposed a higher prevalence of injuries in children who were active in competitive sports since in their case there would be greater possibilities of injury not only during training but also in competition. Children involved in competitive sport did indeed display a higher incidence of injury; however, the difference between the two groups of youngsters was not statistically significant. This was probably due to the fact that the youngsters surveyed were attending schools with extended sports activities and significant differences between the two groups were thus eliminated. Research studies dealing with a similar topic are rare. One example concerned university students and here the authors (Biazevic et al., 2010) concluded that those participating in sport had a 3.45-times greater chance of dental injury than those students who did not.

In addition to injuries to teeth, oral cavity, jaw and the head, children doing sport may also sustain a whole series of injuries to fingers, elbows and ankles, including fractures of the upper and lower limbs. Williams et al. (1998) recorded the incidence of injuries in children practising sport on a regular basis and children doing so only occasionally in their free time. This research showed $32.2 \%$ of children had suffered injuries during sport. In present questionnaire study $42.8 \%$ of children mentioned having sustained an injury during sport. However, a significant statistical difference between the cohort of children engaged in competitive sport and those doing sport only in school lessons and recreationally was not ascertained.

\section{Conclusion}

Sport-related injuries, including dental traumas, are a hazard not only for children engaged in competitive sport but also in children performing sport only at school and recreationally in their free time. The occurrence of TDI was higher but not statistically significant among pupils who are involved in competitive sports. No significant difference between girls and boys was found in current study. The most of children sustained orofacial injuries during trainings and competitions. Sport-related injuries differ from other types of injury in that they are foreseeable and can be avoided by appropriate protection. Current questionnaire revealed that the use of sports mouthguards by children doing competitive sport is minimal.

\section{References}

Andersson, L. (2013). Epidemiology of traumatic dental injuries. J Endod, 39 (3), 82-85.

Andreasen, J.O., Andreasen, F.M., Andersson, L. (2007). Textbook and color atlas of traumatic injuries to the teeth. 4th ed. Copenhagen: Blackwell Munksgaard.

Andreasen, J.O., Ravn, J.J. (1972). Epidemiology of traumatic dental injuries to primary and permanent teeth in a Danish population sample. Int J Oral Surg, 1 (5), 235-239.

Atabek, D., Alaçam, A., Aydintuğ, I., Konakoğlu, G. (2013). A retrospective study of traumatic dental injuries. Dent Traumatol, 30 (2), 154-161.

Biazevic, M.G.H., Michel-Crosato, E., Detoni, Â., Klotz, R., de Souza, E.R., de Paula Queluz, D. (2010). Orofacial injuries in sports and use of mouthguards among university students. Braz J Oral Sci, 9 (3), 380-383.

Borsen, A., Holm, A.K. (1997). Traumatic dental injuries in a cohort of 16-year-olds in northern Sweden. Dent Traumatol, 13 (13), 276-280.

Bücher, K., Neumann, C, Hickel, R, Künish, J. (2013). Traumatic dental injuries at a German University Clinic 2004-2008. Dent Traumatol, 29 (2), 127-133.

Damé-Teixeire, N., Severo Alves, L., Susin, C., Maltz, M. (2013).Traumatic dental injury among 12-year old South Brazilian schoolchildren: prevalence, severity, and risk indicators. Dent Traumatol, 29 (1), 52-68.

Davis, G.T., Scott, S.C. (1984). Dental trauma in Australia. Aust Dent J, 29 (4), $217-221$. 
Fakhruddin, K.S., Lawrence, H.P., Kenny, D.J., Locker, D. (2007). Use of mouthguards among 12-to 14-year-old Ontario schoolchildren. J Can Dent Assoc, 73 (6), 505-505e.

Federation Dentaire International (FDI). (1990). Commission on dental products, Working Party No. 7, 1990.

Gassner, R., Bosch, R., Tuli, T., Emshoff, R. (1999). Prevalence of dental trauma in 6,000 patients with facial injuries. Oral Surg Oral Med Oral Pathol Oral Radiol Endod, 87 (1), 27-33.

Gassner, R., Tuli, T., Hächl, O., Moreika, R., Ulmer, H. (2004). Craniomaxillofacial trauma in children: a review of 3,385 cases with 6,060 injuries in 10 years. J Oral Maxillofac Surg, 62 (4), 399-407.

Glendor, V. (2008). Epidemiology of traumatic dental injuries - a 12 year review of literature. Dent Traumatol, 24 (6), 603-611.

Hecova, H., Tzigkounakis, V., Merglova, V., Netolicky, J. (2010). A retrospective study of 889 injured permanet teeth. Dent Traumatol, 26 (6), 466-475.

Heintz, W. (1968). Mouth protectors: a progress report. J Am Dent Assoc, 77 (3), 632-636.

Lang, B., Pohl, Y., Filippi, A. (2002). Knowledge and prevention of dental trauma in team handball in Swizerland and Germany. Dent Traumatol, 18 (6), 329-334.

Lexomboon, D., Carlson, C.H., Andresson, R., von Bultzingslowen, I., Mensah, T. (2016). Incidence and causes of dental trauma in children living in the county of Värmland, Sweden. Dental Traumatol, 32 (1), 56-64.

Marcenes, W., Zabot, N.E., Traebert, J. (2001). Socio-economic correlates of traumatic injuries to the permanent incisors in schoolchildren aged 12 years in Blumenau, Brazil. Dent Traumatol, 17 (5), 222-226.

Ozbay, G., Bakkal, M., Abbasoglu, Z., Demirel, A., Kargul, B., Welbury, R. (2013). Incidence and prevention of traumatic injuries in paediatric handball players in Istanbul, Turkey. Eur Arch Paediatr Dent, 14 (1), 41-45.

Perunski, S., Lang, B., Pohl, Y., Filippi, A. (2005). Level of information concerning dental injuries and their prevention in Swiss basketball - a survey among players and coaches. Dent Traumatol, 21 (4), 195-200.

Porritt, J.M., Dawn Rodd, H., Baker, S.R. (2011). Quality of life impacts following childhood dento-alveolar trauma. Dent Traumatol, 27 (1), 2-9.

Rodd, H.D., Chesham, D.J. (1997). Sports-related oral injury and mouthguard use among Sheffield school children. Community Dent Health, 14 (1), 25-30.

Rocha, M.J.C., Cardoso, M. (2001). Traumatized permanent teeth in Brazilian children assisted at the Federal University of Santa Catarina, Brazil. Dent Traumatol, 17 (6), 245-249.

Sane, J., Ylipaavalniemi, P. (1988). Dental trauma in contact team sports. Endo Dent Traumatol, 4 (4), 164-169.

Schulze, A. (2008). The use of mouth protectors in sports. CSMI (Clinical Sports Medicine International), 1 (8), $20-23$.

Skaare, A.B., Jacobsen, I. (2003). Dental injuries in Norwegian aged 7-18 years. Dent Traumatol, 19 (1), 67-71.

Taiwo, O.O., Jalo, H.P. (2011). Dental injuries in 12-year old Nigerian students. Dent Traumatol, 27 (3), 230-234.

Traebert, J., Peres, M.A., Blank, V., Boell, R.D., Pietruza, J.A. (2003). Prevalence of traumatic dental injury and associated factors among 12-year-old school children in Florianópolis, Brazil. Dent Traumatol, 19 (1), 15-18.

Williams, J.M., Wright, P., Currie, C., Beattie,T.F. (1998). Sports related injuries in Scottish adolescents aged 11-15. Br J Sports Med, 32 (4), 291-296

Cite this article aS: Merglova, V. (2018). Sport-Related Traumatic Injuries Among Schoolchildren (a Questionnaire Study). Central European Journal of Sport Sciences and Medicine, 2 (22), 61-68. DOI: 10.18276/cej.2018.2-07. 